\title{
A MÚSICA NO CURRÍCULO DA EDUCAÇÃO DE JOVENS E ADULTOS: UM ESTUDO DE CASO
}

\author{
Music in the curriculum of youth and adult \\ education: a case study
}

\author{
Música en el currículo de la educación de \\ jóvenes y adultos: un estudio de caso
}

\author{
Daniela Cesa Fracasso \\ Universidade Federal do Rio Grande do Sul \\ dani_fracasso@yahoo.com.br
}

\begin{abstract}
Resumo: Este artigo apresenta os resultados de pesquisa que teve como objetivo compreender a inserção do ensino de música no currículo da educação de jovens e adultos (EJA). A pesquisa se orientou teoricamente por proposições do campo dos estudos do currículo, mais especificamente, pelo entendimento de que o currículo é o núcleo estruturante da função da escola, um espaço político de legitimação e reconhecimento de saberes e de sujeitos. A escolha metodológica foi o estudo de caso, por meio da abordagem qualitativa. Como resultado destaca-se o reconhecimento dos sujeitos como princípio orientador da inserção da música no currículo. A música ocupa dois espaços no currículo, nas totalidades iniciais e nas oficinas do Centro Musical, cada qual com diferentes finalidades e formas de organização e de condução das práticas pedagógicas. Como ponto comum está o reconhecimento das experiências sociais no currículo, aproximando saberes e sujeitos.
\end{abstract}

Palavras-chave: Ensino de música. Currículo. Educação de jovens e adultos.

Abstract: This paper presents the findings of a research that aimed to understand the insertion of music teaching in the curriculum of youth and adult education (EJA). The research oriented itself theoretically by propositions of the curriculum study field, more specifically, by the understanding that the curriculum is the structuring core of the school's role, a political space for legitimization and acknowledgement not only of knowledge, but, mainly, of individuals. The methodology choice was a case study through a qualitative approach. The findings point out to the acknowledgement of the individuals as the guiding principle for the insertion of music in the curriculum. The two spaces occupied by music as a curricular component present themselves with distinct goals, different forms of organization as well as distinct ways of carrying out the educational practices. In both, however, the social experiences are acknowledged in the curriculum, straitening the relation between knowledge and individuals.

Keywords: Music teaching. Youth and adult education. Curriculum.

Resumen: Este artículo presenta los resultados de una investigación que tuvo como objetivo comprender la inserción de la enseñanza de la música en el currículo de educación de jóvenes y adultos (EJA). La investigación se guió teóricamente por propuestas desde el campo de los estudios curriculares, más específicamente, por el entendimiento de que el currículo es el núcleo estructurante de la función de la escuela, un espacio político para legitimar y reconocer conocimientos y sujetos. La metodología elegida fue el estudio de caso, utilizando el enfoque cualitativo. Como resultado, se destaca el reconocimiento de los sujetos como principio rector para la inserción de la música en el currículo. La música ocupa dos espacios en el currículo, en las totalidades iniciales y en los talleres del Centro Musical, cada uno con diferentes propósitos y formas de organización y conducción de las prácticas pedagógicas. Como punto común está el reconocimiento de las experiencias sociales en el currículo, acercando conocimientos y sujetos.

Palabras clave: Enseñanza de la música. Currículo. Educación de jóvenes y adultos. 


\section{Minha História}

Seu moço, quer saber, eu vou contar num baião

Minha história pra o senhor, seu moço, preste atenção

Eu vendia pirulito, arroz doce, mungunzá

Enquanto eu ia vender doce, meus colega iam estudar

A minha mãe, tão pobrezinha, não podia me educar

A minha mãe, tão pobrezinha, não podia me educar

E quando era de noitinha, a meninada ia brincar

Vixe, como eu tinha inveja, de ver o Zezinho contar:

- O professor ralhou comigo, porque eu não quis estudar

- O professor ralhou comigo, porque eu não quis estudar

Hoje todos são doutor, eu continuo joão-ninguém

Mas quem nasce pra pataca, nunca pode ser vintém

Ver meus amigo doutor, basta pra me sentir bem

Ver meus amigo doutor, basta pra me sentir bem

Mas todos eles quando ouve, um baiãozinho que eu fiz,

Ficam tudo satisfeito, batem palmas e pedem bis

E diz: - João foi meu colega, como eu me sinto feliz

E diz: - João foi meu colega, como eu me sinto feliz

Mas o negócio não é bem eu, é Mané, Pedro e Romão, Que também foi meus colegas, e continuam no sertão

Não puderam estudar, e nem sabe fazer baião

Não puderam estudar, e nem sabe fazer baião

João do Vale

\section{INTRODUÇÃO ${ }^{1}$}

Este artigo apresenta resultados da pesquisa, por mim conduzida entre os anos de 2013 e 2015, que teve como objetivo compreender a inserção do ensino de música no currículo da educação de jovens e adultos (EJA). ${ }^{2}$ Como objetivos específicos, busquei identificar os processos envolvidos na inserção do ensino da música como componente curricular da EJA; conhecer os sujeitos envolvidos nesse processo; e analisar o que, como, para que, por quem e para quem é ensinado.

\footnotetext{
1 Uma primeira versão deste texto foi apresentada no XVIII Encontro Regional Sul da Associação Brasileira de Educação Musical e publicada nos anais do evento (Fracasso, 2018).

2 Trata-se da dissertação de mestrado defendida no Programa de Pós-Graduação em Música da Universidade Federal do Rio Grande do Sul, em 2015, sob orientação da professora Luciana Del-Ben.
} 
A pesquisa teve como ponto de partida minha primeira experiência como professora de música na EJA. A escola em que eu iria trabalhar tinha como proposta oferecer música, teatro e artes visuais como componentes curriculares obrigatórios. Sendo a EJA um contexto bastante específico e diferente daqueles pelos quais eu já havia passado na educação básica, me surgiram alguns questionamentos sobre como trabalhar com o ensino de música nesse contexto. Para organizar a minha prática, de modo que os alunos pudessem ter experiências significativas com o ensino de música, busquei suporte em documentos oficiais que orientassem o ensino de música para a EJA.

A educação de jovens e adultos, como modalidade, tem suas diretrizes curriculares orientadas pelo Parecer CNE/CEB n ${ }^{0}$ 11/2000 (Brasil, 2000), de forma a contemplar as suas especificidades. Embora, no decorrer da pesquisa, eu tenha feito novas e diferentes leituras desse documento e, até mesmo, tenha me distanciado dele durante o trabalho, considero relevante apresentá-lo aqui, pois teve papel importante na construção da questão central da minha pesquisa.

O texto do parecer, que se referia à arte no currículo da EJA, dizia que

os componentes curriculares ligados à Educação Artística e Educação Física são espaços oportunos, conquanto associados ao caráter multidisciplinar dos componentes curriculares, para se trabalhar a desinibição, a baixa autoestima, a consciência corporal e o cultivo da socialidade. Desenvolvidos como práticas socioculturais ligadas às dimensões estética e ética do aluno, estes componentes curriculares são constituintes da proposta pedagógica de oferta obrigatória e frequência facultativa (Brasil, 2000, p. 63).

Em uma primeira leitura, me chamaram a atenção as finalidades relacionadas a esses componentes - "trabalhar a desinibição, a baixa autoestima, a consciência corporal e o cultivo da socialidade" -, não por considerar que não façam parte desses componentes, mas por serem bastante genéricas, e o fato de indicar a "frequência facultativa".

Para ampliar a compreensão sobre o ensino de música na EJA, recorri à literatura da área. No que parece ser um dos primeiros trabalhos sobre o tema na área de educação musical, Fernandes (2005) reflete sobre a educação musical na EJA de escolas municipais do Rio de Janeiro. O autor faz considerações críticas sobre a forma como o ensino da música era descrito nos documentos nacionais e municipais, indicando que as propostas curriculares estariam construídas no princípio da "educação ingênua", em que o "aluno adulto e das classes populares é tido como ignorante" (Fernandes, 2005, p. 40).

Já Ribas (2009, p. 133), ${ }^{3}$ ao investigar as aprendizagens musicais entre sujeitos de diferentes gerações a partir de uma perspectiva sociológica, identifica múltiplas formas de ensino e aprendizagem da música estabelecidas no

3 Outros trabalhos publicados pela autora: Ribas (2006a, 2006b, 2014). 
contexto da EJA, e a música como uma "prática social marcante nas trajetórias e vivências pessoais" dos entrevistados.

Outros trabalhos apresentavam questões relacionadas à música na EJA por diferentes perspectivas - como resultados parciais de pesquisa em andamento cujo objetivo era "refletir sobre o ensino de Arte/Música na Educação de Jovens e Adultos" (Prazeres; Machado, 2011, p. 2334), os saberes necessários para ensinar música na EJA (Saúl, 2013), e o relato de experiências vivenciadas com alunos de EJA no projeto "Ouvir, criar e tocar: o processo de desconstrução e reconstrução do fazer musical” (Abreu, 2014, p. 320). Entretanto, não abordavam os processos envolvidos na inserção do ensino de música no currículo da educação de jovens e adultos.

Novos trabalhos foram publicados nos anos seguintes à conclusão da pesquisa, entre eles, os de Oliveira, R. (2016); Oscar e Bastos (2016); Gonzaga e Morato (2017); Henderson (2017a, 2017b); Henderson, Henderson e Chada (2017); Vieira (2017); Balzan e Cunha (2018); Duarte (2018); Wolffenbüttel e Sant'Anna (2018); Gonzaga e Gonçalves (2020); e Oliveira e Beineke (2020). Embora o número de publicações sobre essa temática tenha crescido, boa parte delas se configura como relatos de experiência. Wolffenbüttel e Sant'Anna (2018, p. 6), ao realizarem um levantamento de pesquisas sobre EJA publicadas em periódicos da área de música, especificamente a Revista da Abem e a revista Opus, constataram a existência de apenas quatro artigos, indicando a relevância de mais investigações e publicações sobre essa temática. Dessa forma, entendo que este artigo possa contribuir para as reflexões da área de educação musical sobre o ensino de música na educação de jovens e adultos, nas suas especificidades como modalidade e possiveis aproximações com outros contextos.

Para contextualizar a EJA, apresento, a seguir, um breve histórico dessa modalidade, bem como as características dos sujeitos a quem ela se destina.

\section{SOBRE A EDUCAÇÃO DE JOVENS E ADULTOS: SUA HISTÓRIA E SEUS SUJEITOS}

As particularidades da EJA como modalidade da educação básica se mostram tanto pela sua trajetória no contexto político e social do Brasil quanto, e especialmente, pelos sujeitos a quem ela se destina.

A EJA faz parte de um contexto político, econômico e social, e surge de um cenário de exclusão e desigualdades. Ao longo da história, essa modalidade de ensino passou por diferentes formas de organização. As primeiras iniciativas registradas tinham como meta a redução do índice de analfabetismo. O reconhecimento da educação como um direito fundamental surge na década de 1960 com o Movimento de Cultura Popular (MCP), que tinha Paulo Freire como uma das figuras centrais. O MCP defendia a educação como direito, como ato político e como forma de transformação social, com o olhar para os sujeitos e seus contextos. Essas propostas e concepções de educação, entendendo a educação como ato político, foram um marco para a educação de jovens e adultos e deixaram heranças que permaneceram nessa modalidade de ensino ao longo do tempo (Arroyo, 2005; Fávero, 2009; Oliveira, I., 2007; Souza, 2011). 
Ainda assim, as políticas para a educação de jovens e adultos, muitas vezes, reforçam a ideia que Ciavatta e Rummert (2010, p. 463) definem como uma "marca social da escola", em que "cada grupo social possui um tipo de escola próprio". Nesse mesmo sentido, Arroyo (2005, p. 221) percebe a educação de jovens e adultos como uma história com muito mais tensões do que a da educação básica regular, indicando que

os olhares tão conflitivos sobre a condição social, política, cultural desses sujeitos [da EJA] têm condicionado as concepções diversas da educação que lhes é oferecida. Os lugares sociais a eles reservados - marginais, oprimidos, excluídos... - têm condicionado o lugar reservado a sua educação no conjunto das políticas oficiais. A história oficial da EJA se confunde com a história do lugar social reservado aos setores populares. É uma modalidade do trato dado pelas elites aos adultos populares.

Esses sujeitos, jovens e adultos populares, a quem se destina a educação de jovens e adultos, têm como características gerais serem trabalhadores ou pessoas em busca de trabalho, com contextos de vida diversificados, que confluem em diferentes formas de exclusão (política, econômica, social, cultural). São jovens e adultos que não tiveram acesso à escola básica no tempo regular ou, como o caso de muitos dos jovens da EJA, que foram excluídos pelo alto índice de repetência. Além disso, são "protagonistas de histórias reais e ricos em experiências vividas [...] configurando tipos humanos diversos" (Brasil, 2006, p. 4). Em sua maioria, vivem no mundo do trabalho com responsabilidades sociais e familiares e com valores já construídos em relação aos seus contextos sociais (Brasil, 2006, p. 4). A compreensão das dimensões da condição humana desses estudantes é fundamental para as experiências de educação, pois elas orientam as especificidades da EJA (Arroyo, 2005, p. 233). O reconhecimento dessas experiências no currículo escolar é igualmente fundamental. Isso me levou ao entendimento de currículo como espaço de reconhecimento de saberes e de sujeitos.

\section{O CURRÍCULO: ESPAÇO DE RECONHECIMENTO DE SABERES E SUJEITOS}

A proposta de investigar o processo de inserção da música no currículo deu-se por acreditar que esse é um espaço político, de legitimação e de reconhecimento de saberes ${ }^{4}$ e de sujeitos. A partir de Arroyo (2011), compreendi esse espaço como território, um território disputado. Para esse autor,

\footnotetext{
4 Saberes, na perspectiva adotada pelas Diretrizes Curriculares Nacionais para a Educação Básica, são "conjunto de experiências culturais, senso comum, comportamentos, valores, atitudes, em outras palavras, todo o conhecimento adquirido pelo estudante nas suas relações com a família e com a sociedade em movimento" (Brasil, 2013, p. 25), o que seria contraposto aos conhecimentos historicamente construídos. Opto por utilizar o termo "saberes", entendendo que ele dá conta dos múltiplos conhecimentos que fazem parte dos sujeitos, sejam eles os conhecimentos ditos legitimados, sejam aqueles a que se referem as Diretrizes Curriculares Nacionais para a Educação Básica.
} 
na construção espacial do sistema escolar, o currículo é o núcleo e o espaço central mais estruturante da função da escola. Por causa disso, é o território mais cercado, mais normatizado. Mas também o mais politizado, inovado, ressignificado (Arroyo, 2011, p. 13).

No currículo estão implicadas relações políticas e de poder, e são disputados espaços de conhecimento: conhecimentos institucionalizados e conhecimentos dos sujeitos que vivem o currículo. O reconhecimento dos sujeitos é fundamental para que as relações que se estabelecem entre saberes e sujeitos sejam valorizadas, de forma que o currículo seja entendido como prática de significação. Como afirma Macedo (2012, p. 734),

a escola não pode se contentar em ensinar a linguagem [de uma comunidade racional], em transformar o sujeito em representante dessa linguagem, sob pena de torná-lo um sujeito genérico. [...] É preciso deixar emergir o sujeito como aquele que surge como o inesperado.

Nessa perspectiva, é possivel perceber o currículo para além de conteúdos programáticos. Para Arroyo (2011, p. 121), é urgente que as experiências dos educandos se façam presentes no currículo, e reconhecer "que todo conhecimento tem origem na experiência social é mais do que uma questão epistemológica, é uma questão política e pedagógica".

Assim, entendo o currículo como um espaço complexo e em movimento, em que convivem diferentes sujeitos e saberes. O currículo se legitima por meio de práticas reais, aquelas que são vivenciadas pelos sujeitos que delas participam. Essa concepção parece fundamental para que se reconheça o protagonismo dos sujeitos, de forma que eles encontrem sentido e se vejam reconhecidos no currículo escolar. Com base nesse entendimento de currículo, defini os caminhos metodológicos da pesquisa, apresentados a seguir.

\section{Metodologia}

Para a investigação, adotei como estratégia de pesquisa o estudo de caso, por meio de uma abordagem qualitativa. Como caso, foi escolhido o CMET Paulo Freire. No ano de 2013, segundo informações da Secretaria Municipal de Educação de Porto Alegre/RS, essa era a única escola da rede municipal a oferecer música no currículo para a EJA em 2014, ano em que aconteceria a coleta dos dados. Isso acabou por definir o CMET Paulo Freire como o campo da pesquisa.

As técnicas para a coleta dos dados foram observações, análise de documentos e entrevistas semiestruturadas. As observações foram realizadas em uma turma de música dos anos iniciais do ensino fundamental e em oficinas de flauta doce, técnica vocal e canto livre. O período das observações foi de abril a junho de 2014. Por ter feito observações de modo mais sistematizado e frequente nas aulas de música dos anos iniciais do ensino fundamental, 
os alunos e as alunas dessa turma foram os contemplados nas entrevistas. As entrevistas foram realizadas entre julho e agosto de 2014. Os sujeitos entrevistados foram dois alunos e três alunas, duas professoras de música e uma professora que assumia a vice-direção da escola naquele momento. ${ }^{5} \mathrm{~A}$ participação na etapa das entrevistas se deu por adesão.

Os resultados da análise de dados, apresentada a seguir, buscam contextualizar o campo da pesquisa e os sujeitos entrevistados, bem como apresentar o processo de inserção da música no CMET Paulo Freire e os diferentes espaços por ela ocupados no currículo.

\section{CMET PAULO FREIRE: O CAMPO DA PESQUISA}

Contextualizar o campo da pesquisa é importante para compreender o processo de inserção da música no currículo escolar e a forma como as práticas pedagógicas se organizavam na escola. O CMET Paulo Freire tem origem nas turmas do Serviço de Educação de Jovens e Adultos (Seja) em 1989, construindo assim uma longa trajetória na educação de jovens e adultos na cidade de Porto Alegre, o que faz dela uma escola-referência para essa modalidade. No ano de 2014, o CMET Paulo Freire era a única escola do município que atendia exclusivamente a EJA nos três turnos. Na sua história se mostra como uma escola em permanente movimento, tanto pelos lugares por que passou, ocupando diferentes sedes, quanto pela organização pedagógica e curricular. Esses dois fatores em movimento - o espaço físico e a organização curricular - refletem, também, no ensino de música.

O CMET Paulo Freire tem sua organização curricular por totalidades de conhecimento. Essa proposta compreende que os diferentes saberes estão inter-relacionados, estruturando o ensino de maneira global, de forma que os conhecimentos sejam construídos e aprofundados, aumentando o nível de complexidade nas diferentes etapas (Andrejew; Veronese; Spielmann; Ckless; Silva; Assis, 2004, p. 106). Elas estão divididas em totalidades iniciais (alfabetização) e totalidades finais (pós-alfabetização), contemplando todo o ensino fundamental.

Seu currículo e fundamentos filosóficos estão pautados a partir da perspectiva freiriana de educação popular, tendo como princípios orientadores a construção plena da cidadania; a transformação da realidade; a construção da autonomia moral e intelectual; e a educação como direito de todos (Prefeitura Municipal de Porto Alegre, [2014], p. 15). Sendo assim,

o processo pedagógico tem como referência a concepção dialógica, em que o conhecimento de jovens e adultos, adquirido em suas experiências de vida, é relacionado com o conhecimento historicamente construido pela humanidade, de forma que tanto o conhecimento específico dos alunos como o

\footnotetext{
5 Os participantes são identificados por seus nomes reais ou pseudônimos escolhidos por eles. A utilização dos nomes reais foi indicada e autorizada pelos entrevistados.
} 
sistematizado sejam problematizados, recriados e reelaborados para explicar as situações cotidianas destes sujeitos (Andrejew; Veronese; Spielmann; Ckless; Silva; Assis, 2004, p. 105).

Quando iniciei a coleta de dados, em abril de 2014, a escola assumia dois currículos: o currículo escolar e o currículo permanente ao longo da vida. Nesse mesmo tempo o projeto político-pedagógico estava sendo reelaborado e, no final do ano de 2014, a escola funde ambos os currículos propondo o currículo de educação permanente ao longo da vida, por entender que os currículos estavam relacionados e que as pessoas estão em permanente processo de formação (Prefeitura Municipal de Porto Alegre, [2014], p. 4). Na discussão e análise dos dados, entretanto, faço referência aos dois currículos que estavam vigentes no período em que realizei a pesquisa no campo. O currículo escolar compreendia as totalidades iniciais e finais, e o currículo permanente ao longo da vida, as oficinas de diferentes áreas, incluindo o Centro Musical com as oficinas de música.

Essa forma de organização curricular - tanto a de dois currículos quanto a do currículo de educação permanente ao longo da vida - possibilitava que, mesmo que o aluno concluísse as etapas do ensino fundamental, ele pudesse permanecer na escola se desenvolvendo em áreas de seu interesse e cultivando as relações que ali se estabeleceram. Possibilitava, também, que tanto estudantes quanto docentes encontrassem espaços para o reconhecimento de si e das suas experiências no currículo. Possibilitava "trabalhar o ensinar-aprender sobre as experiências de vida dos seus sujeitos, [...] aproximar mestres e alunos entre si e com os conhecimentos" (Arroyo, 2011, p. 153).

Quanto ao público que o CMET Paulo Freire atende, ele é composto por jovens, adultos e idosos, com características comuns àquelas apresentadas anteriormente. Como indicado pelas professoras entrevistadas, o público jovem tem aumentado na escola e é predominante nas etapas das totalidades finais. Já os adultos e idosos se encontram em maioria nas totalidades iniciais.

\section{OS SUJEITOS DA PESQUISA: ALUNOS, ALUNAS E PROFESSORAS ENTREVISTADAS}

Dos alunos entrevistados, Henrique, 43 anos, estava no CMET Paulo Freire desde 1994. Largou a escola quando jovem por dificuldades voltadas à leitura, o que o fazia sentir-se excluído daquele espaço. Quando relacionava sua primeira experiência com a escola e sua experiência atual, dizia que "hoje as pessoas são mais tranquilas, um ajuda o outro, a gente interage" (Henrique). Essa fala permite perceber que se sentia acolhido pela escola. Suas experiências musicais se deram por meio do CMET Paulo Freire. Além das aulas de música das totalidades iniciais, já havia participado do coro no Centro Musical.

João, 48 anos, também estava no CMET Paulo Freire há bastante tempo. Não sabia dizer com exatidão, mas entrou entre os anos de 1995 e 1999, quando a sede da escola ficava na rua General Vitorino. Suas experiências 
escolares foram apenas na idade adulta e, além do CMET Paulo Freire, tinha frequentado uma outra instituição. Quando compara as duas experiências, diz que ficou um tempo na outra escola, "mas não conseguia muito... não desenvolvia muito. Agora, aqui [no CMET], tá!" (João). O que mais gostava na escola era de escrever. Com relação à música, tinha como referência a família: "A metade da minha família, a maioria são todos músicos. Um toca gaita, cada um toca um instrumento. Quer juntar tudo mesmo? Acho que dá do tamanho do colégio" (João). Além da família e da escola, tinha experiências com música na igreja.

Das três alunas entrevistadas, todas tinham como profissão empregada doméstica e estavam aposentadas. Vera, 65 anos, estava no CMET Paulo Freire há três anos. Parou de estudar quando criança e retomou os estudos após a aposentadoria. Entrou na escola, principalmente, para aprender a ler, como disse: "Pelo menos pra eu ler um jornal, que eu adoro. Eu acho tão bonito, assim, as pessoas lerem e eu não conseguir ler..." (Vera). As experiências com música, assim como João, vieram da família:

Meu pai tocava, meu pai era baterista. Meu pai tocava tudo, qualquer instrumento de couro ele tocava. Meu irmão também era, adorava uma bateria. Então eu tinha assim... o pessoal de casa. Todo o pessoal de casa, minha mãe gostava também. Toda família era da música, né?! Então nasci com esse sangue (Vera).

Percebia o CMET Paulo Freire como uma escola que possibilitava aos alunos aprenderem muitas coisas diferentes, pelas aulas, oficinas e cursos que oferece: "Aqui eles oferecem muita coisa boa" (Vera).

Rosalinda, 73 anos, estava no CMET Paulo Freire há um ano. Quando criança, frequentou a escola entre os 12 e 13 anos e parou de estudar para ajudar a família no trabalho na roça. Sua motivação para voltar à escola foi a leitura e escrita. Dentre as coisas que mais gostava na escola estavam as aulas de canto, as aulas de ginástica e as de informática. As referências com música, como contou Rosalinda, também vinham da família: "Meu pai e minha mãe tocavam violão. Era pra eu tocar. Eu gosto de piano. Eu adorava piano. [...] Eu tocava piano sem ninguém me ensinar. As pessoas diziam que eu tinha mão boa pra piano. Mas piano é mais caro."

Beni, 64 anos, não sabia dizer há quanto tempo estava no CMET Paulo Freire. Sua referência era que tinha entrado quando a sede ainda era no centro de Porto Alegre. Assim como os demais, estava na escola para aprender a ler e a escrever. Teve uma infância e uma adolescência bastante dificeis. Lembra que desde cedo já trabalhava como doméstica. Nessa época frequentou a escola por pouco tempo. Na experiência atual, percebia a escola como um lugar de convivência, e o que mais gosta são as companhias e as professoras. As experiências que teve com música foram na escola: nas aulas de música das totalidades iniciais e quando frequentou as oficinas de flauta doce do Centro Musical. Apesar de não participar mais das oficinas, contava que, 
eventualmente, pegava a flauta para tocar em casa: "Às vezes, eu pego pra tocar. Os passarinhos ficam só me olhando... e eu lá, tentando tocar" (Beni).

Dos alunos e alunas entrevistadas, o que considero importante observar é que suas histórias de vida e suas experiências com a escola ratificam as asserções sobre as características dos sujeitos da EJA, identificadas na literatura. Como afirmou Arroyo (2005), a condição social e humana dos jovens e adultos que inspiraram o movimento da educação popular continua atual. Nas falas dos alunos ficava evidente que buscaram a escola por algo objetivo e associavam o conhecimento construído nessa instituição a questões práticas das suas vidas. Além disso, demonstravam ter consciência do que não sabiam e do queriam aprender e, por isso, estavam ali. Isso fazia com que o tempo que esses alunos permanecessem na escola fosse, muitas vezes, um tempo mais longo do que o da a educação básica regular. Esse tempo refletia nas relações que estabeleciam com a escola e com as pessoas que conviviam nesse espaço. Também chamou minha atenção que, para a maioria deles, a música fazia parte das suas vivências não só na escola, mas fora dela, e era algo com que eles se identificavam.

Quanto às professoras entrevistadas, todas tinham uma longa trajetória no CMET Paulo Freire. Dione ocupava o cargo de vice-diretora da escola, trabalhava no CMET Paulo Freire desde o início da sua fundação, quando ainda eram as turmas do Seja, em 1989. Saadya, que assumia as aulas do Centro Musical, trabalhava no CMET Paulo Freire desde 1991, e Daisy, professora de música das totalidades iniciais, estava há 15 anos na escola. Nas suas trajetórias nessa instituição participaram de forma ativa de diferentes momentos da construção da proposta pedagógica da escola.

Sobre essas professoras, ressalto alguns pontos que considero características comuns entre elas e que me permitiram entender a forma como o ensino de música tinha espaço no currículo da escola, conhecendo o processo desde o início. Em suas falas, foi possivel perceber que encaravam a educação como um ato de integração de conhecimentos, vivências, experiências, de formação humana. O olhar atento para os alunos da EJA aparecia em diversos momentos, de forma direta ou indireta. Entendiam que a escola, para esses alunos, deveria ser um lugar que fosse além do ensino, um lugar que oportunizasse diferentes vivências, um lugar em que eles se sentissem felizes e acolhidos, que pudessem se desenvolver em diferentes áreas, de acordo com seus interesses, suas vivências e experiências. Reconheci nessas professoras características comuns às descritas por Arroyo (2011, p. 125), quando diz que

há docentes que se propõem que os educandos encontrem como objeto do conhecimentos curricular entender-se e ampliar os significados de suas experiências sociais, humanas, de suas relações com o espaço, das vivências dignas ou indignas de seu tempo humano, cultural, de seus processos de socialização.

Embora com formação em diferentes áreas do conhecimento, convergiam na ideia de que a arte dentro da escola tinha um papel importante para 
os alunos, para que eles pudessem se expressar utilizando diversas linguagens. As três professoras iniciaram sua trajetória na escola como pedagogas nas totalidades iniciais, mas essa identificação com a arte ficava explicita nas suas falas. Especificamente quanto às professoras de música, o fato de não entrarem na escola com essa função, mas buscarem ocupar esse lugar, confirmava o vínculo que tinham com a área e seu protagonismo no processo de inserção da música no currículo dessa escola.

\section{O ENSINO DE MÚSICA NO CURRÍCULO DO CMET PAULO FREIRE}

O ensino de música no CMET Paulo Freire ocupava dois espaços diferentes no currículo da escola. Eram eles: o Centro Musical, que oferecia oficinas de instrumentos, técnica vocal e canto livre, além das atividades de canto coral e práticas musicais coletivas; e as aulas de músicas nas totalidades iniciais. No momento da pesquisa, quando a escola ainda se organizava por dois currículos, esses espaços estavam distribuídos com o Centro Musical como parte do currículo permanente ao longo da vida e as aulas de música nas totalidades iniciais do currículo escolar. O currículo escolar atendia os alunos regularmente matriculados na escola, e o currículo permanente ao longo da vida, a esses mesmos alunos e à comunidade externa.

Esses dois espaços de ensino de música não existiram na escola desde sempre. Eles foram sendo construídos, conquistados e, como observou a professora Daisy, essas conquistas não tinham relação com a legislação, mas com demandas da comunidade escolar e do reconhecimento da diversidade de sujeitos e experiências, como forma de "enriquecimento do currículo" (Arroyo, 2011 , p. 148). O processo de inserção do ensino de música acompanha a história da escola.

As primeiras atividades iniciaram com a professora Saadya, que, além de ser pedagoga, tinha formação em musicoterapia. Ela conta que "buscava nas horas de folga, como durante o recreio, pessoas que tocassem violão, gostassem de cantar, buscando estimular tal prática" (Saadya). Entrando para o corpo docente da escola um professor de teatro e uma professora de artes visuais, inicia um trabalho integrado entre teatro, música e artes visuais, que resulta em trabalhos específicos de cada uma dessas áreas no currículo do CMET Paulo Freire. Paralelamente a esse trabalho, nos horários após as aulas, Saadya inicia um coro com os alunos que tinham interesse. A música, dessa forma, ganha espaço no currículo e começa a conquistar outros espaços. A partir da consolidação do trabalho com as oficinas de música e tendo respaldo legal pela Ordem de Serviço Municipal de Porto Alegre n 002/2008 (Prefeitura Municipal de Porto Alegre, 2008), cria-se em 2010 o Centro Musical Paulo Freire, e são consolidados os dois espaços da música no currículo: as aulas de música nas totalidades iniciais e o Centro Musical.

Foi possivel perceber, assim, que o ensino de música no CMET Paulo Freire ocupava diferentes espaços no currículo escolar que, embora tivessem propósitos comuns que dialogavam com os princípios orientadores das práticas pedagógicas da escola, se desenvolviam com diferentes finalidades. 
Como pontos comuns, estava a oportunidade que proporcionavam aos jovens, adultos e idosos que frequentavam a escola, sendo eles alunos regularmente matriculados e pessoas da comunidade, de trabalharem com a música e a contribuição para o desenvolvimento humano e para as relações sociais. Entretanto, também assumiam distintas finalidades e organizavam suas práticas pedagógicas de maneiras diferentes.

\section{O Centro Musical Paulo Freire}

O Centro Musical, coordenado pela professora Saadya, acolhia jovens e adultos "de toda a comunidade" (Dione), com diferentes formações, que tinham em comum o interesse em desenvolver ou aprofundar seus conhecimentos musicais.

Tem alunos nossos, tem ex-alunos, tem alunos da comunidade, tem aposentados e o que tem em termos de música, então... tem o coral, tem a percussão, tem o violão, tem a flauta, tem o cavaquinho, tem o exercício vocal. $\mathrm{E}$ isso, dentro do currículo de educação permanente ao longo da vida (Dione).

Contava, no seu corpo docente, com três professores com carga horária exclusiva para essa atividade. Estava organizado com oficinas de flauta doce e teoria musical, técnica vocal, violão, cavaquinho, percussão e canto livre e com o coral. As oficinas do Centro Musical, assim como outras oficinas oferecidas pela escola, possibilitavam um espaço para que

pessoas que não conseguem aprender uma matemática da vida e que desistem de estudar, muitas vezes, podem estar se atualizando em outras áreas do conhecimento. Podem estar se realizando, sendo felizes em outras áreas (Saadya).

A partir das entrevistas e das observações, foi possivel perceber que o foco do Centro Musical estava na aprendizagem de habilidades especificas da música, com objetivos voltados à performance musical, e tinha sua organização pensada a partir do nível de aprendizado dos alunos. Essa característica aparecia nas falas das professoras. Dione observa: "No Centro Musical, eu vejo bem essa coisa. A vivência de uma música que... técnica vocal já pra cantar, pra se apresentar em público..." (Dione). Daisy destaca que esse trabalho especializado das oficinas acontecia com grupos específicos que "se reúnem sempre, que estão ensaiando e que estão ali com os instrumentos, estão trabalhando só naquilo" (Daisy). Saadya percebe que o caráter das oficinas

é mais no sentido de "performance" mesmo, diferente da educação musical dentro das matérias do ensino regular. Por meio das oficinas, ensinar e alfabetizar as pessoas musicalmente, trabalhar habilidades para tocar os instrumentos musicais (flauta, cavaquinho, violão, percussão, técnica vocal... são esses) e, paralelamente, alfabetizar na área musical (Saadya). 
Para Saadya, esse trabalho específico com a música também cumpria com outras funções, relacionadas ao desenvolvimento humano de forma geral, tais como socialização, desenvolvimento cognitivo e emocional, entre outras. As apresentações realizadas pelos grupos do Centro Musical também eram vistas como oportunidade para a construção de conhecimento e para ampliar as relações sociais. Sobre as experiências com as apresentações, o aluno Henrique contou que, no tempo em que participou do coral, eles iam cantar em outros colégios e que "era uma experiência interessante [porque ele] ia pra lugares que [ele] não conhecia. [Ele] via uma outra cultura, que as pessoas eram legais" (Henrique).

\section{As aulas de música nas totalidades iniciais}

As aulas de música das totalidades iniciais buscavam trabalhar a música de forma mais ampla, para desenvolver a expressividade, a autoestima, as relações entre os sujeitos e a sociedade, para compartilhar experiências e vivências. Esse espaço possibilitava o acolhimento de alunos que retornavam à escola com o objetivo de aprender a ler e a escrever e aprender matemática e que, muitas vezes, não dispunham de tempo para participar das oficinas ou não se identificavam com elas.

A professora Dione entendia que, nesse espaço, a professora não tinha o intuito de transformar os alunos em "artistas da música", mas, sim, "de viver a música com eles" (Dione). Além disso, as professoras entrevistadas reconheciam nesse espaço a oportunidade para trabalhar de forma interdisciplinar e com os temas geradores selecionados pela equipe de professores da escola.

Daisy, professora responsável por essa atividade, assumia que suas práticas buscavam, sempre que possivel, um trabalho integrado com outros professores. Para o planejamento, levava em consideração o tema gerador escolhido pela escola e as demandas dos alunos. Como disse: "Primeiro, eu penso em trabalhar os conceitos musicais através do que eles trazem" (Daisy).

O olhar da professora às especificidades dos alunos fazia com que suas práticas fossem conduzidas com o objetivo de proporcionar momentos de integração, trabalhando questões mais amplas relacionadas ao desenvolvimento humano. Nesse espaço, as atividades eram planejadas de forma a "buscar sentido dentro daquela aula, trabalhar vários conceitos" (Daisy), valorizando a vivência proporcionada pela música. A partir das observações pude perceber que, embora as aulas de música se organizassem em uma estrutura semelhante, os espaços de diálogo entre os alunos e entre alunos e professora influenciavam no planejamento das atividades, tanto no conteúdo quanto na dinâmica da aula.

Como materiais para as atividades nesse espaço a professora fazia uso de instrumentos de percussão, percussão corporal, voz e movimento corporal. Ela conta: "Eu me valho da percussão, que eu acho muito legal e eu gosto muito de trabalhar com percussão. Eu gosto muito de trabalhar com o corpo; 
e acho que eles precisam também" (Daisy). Ainda sobre o entendimento do seu trabalho, relata:

Mas acho que, atrás disso tudo, tem todo um trabalho que é muito importante pra eles, que é a questão mental. [...] Porque eu acho que os alunos, eles são bem mais velhos, e essa coisa de eles ficarem muito tempo sentados, olhando pra um quadro tentando escrever, eu acho que tem todo um estresse [...]. Então, eu procuro fazer com que eles se movimentem, que eles respirem, trabalho um pouco com o que eu sei com a questão da respiração, da impostação da voz, da harmonia das vozes (Daisy).

Para os alunos e alunas entrevistadas as aulas de música nas totalidades iniciais eram um espaço para desenvolver habilidades musicais, como fala Rosalinda: "Pra mim tá bom porque treina a voz. Porque, às vezes, a gente quer cantar... Por exemplo, eu gosto muito da música romântica, mas, dependendo do som que eu tenho que dar nela, minha garganta não ajuda. Então eu gosto de treinar a música". João também identificava aprendizados específicos da música: "Aprendo a cantar as músicas que a professora ensina. Aprendo os exercícios com a voz. Esses mesmos exercícios eu fazia lá [se referindo às aulas de música da igreja que frequenta], só que não era profundo que nem a professora dá. Ela dá exercício pra gente aprender a respirar [...]."

Esse era também um espaço em que os alunos se sentiam reconhecidos, como aparece na fala de Vera: "Eu gosto da música, eu amo a música. Tanto é que a professora descobriu que eu tenho um quê de bater naquele..."

\section{Sobre os dois espaços}

O protagonismo das professoras foi fundamental para a construção e consolidação dos espaços de ensino de música no currículo da escola, garantindo que as práticas educativo-musicais acontecessem de forma efetiva e estivessem garantidas no currículo do CMET Paulo Freire. A maneira como compreendiam a arte, como agente transformador, também foi um fator fundamental para esse processo. Como disse Dione, a arte "é o verdadeiro sentido do trabalho, de tu poder modificar, alterar, transformar a realidade",

em função de que a arte é tão importante pra o desenvolvimento das pessoas, que ela transforma a vida das pessoas, que faz elas revisarem a sua cidadania, que faz elas buscarem uma autonomia e um direito que elas têm. Então isso a gente fixou [no projeto político pedagógico] (Dione).

\footnotetext{
6 Vera contando sobre a experiência que teve tocando um instrumento de percussão em uma das aulas.
} 
A legitimação desses espaços foi reconhecida também pelos alunos, como aparece na fala da aluna Vera, por exemplo, quando diz: "[...] principalmente nessa escola aqui, a música faz parte do ensino". O reconhecimento da música como ensino e o reconhecimento dos sujeitos no currículo da escola tornavam possivel a aproximação, proposta por Macedo (2012, p. 734), entre educação e ensino, ou seja, o currículo - e a música nesse espaço - como prática de significação. Isso possibilitava que a escola fosse entendida como lugar de ensino, mas também como lugar para viver. Como disse a professora Dione: "Essa escola, ela faz um processo de socialização muito legal e ela não deixa nunca de ensinar."

\section{CONSIDERAÇÕES FINAIS}

Como considerações finais, ressalto que a oferta do ensino de música em dois espaços diferentes no currículo da escola foi possivel pela ação protagonista das professoras e de alunos que se fizeram reconhecidos pela escola e, assim, tiveram o apoio da comunidade escolar e da Secretaria Municipal de Educação.

A proposta de organização curricular por totalidades de conhecimento também contribuía para que o ensino não fosse fragmentado e para que as diferentes áreas fossem reconhecidas pelo currículo, incluindo a de música. Como disse uma das professoras entrevistadas, a arte está inserida dentro da concepção de totalidades de conhecimento.

O caráter dialógico que orientava a construção das propostas pedagógicas do CMET Paulo Freire e o entendimento de que a educação e o ensino acontecem ao longo da vida possibilitavam uma integração entre comunidade escolar e comunidade externa. O ensino de música se fazer presente em dois espaços diferentes do currículo colaborava para que a escola se construísse como um lugar para conviver, para se desenvolver, para preservar os vínculos estabelecidos entre estudantes e escola. Isso contribuia para que essa escola fosse entendida como um lugar para viver e o ensino de música, como integrante desse espaço.

Os dois espaços, com suas diferentes finalidades, cumpriam com o papel que cabe à educação musical. Considerando as entrevistas e as observações, foi possivel perceber que, embora as práticas pedagógico-musicais desses dois espaços fossem pouco integradas, elas se mostravam como complementares, tornando o ensino de música acessível a jovens e adultos, independentemente do seu nivel de escolarização.

Por fim, entendo como contribuições da pesquisa apontar para diferentes possibilidades de inserção da música no currículo da EJA e para diferentes práticas vinculadas ao ensino de música, práticas essas que podem dialogar com outros universos pedagógicos e que permitem ampliar a compreensão da educação que se propõe à formação dos sujeitos que a constroem e a legitimam. 


\section{REFERENCIAS}

ABREU, Sílvia Rejane Teixeira de. O processo de desconstrução e reconstrução do fazer musical de alunos da EJA de uma Escola Estadual da cidade de Rio Branco - AC: relato de Experiência. In: ENCONTRO REGIONAL NORTE DA ABEM, 7., 2014, Rio Branco. Anais [...]. Rio Branco: Abem, 2017, p. 319-329.

ANDREJEW, Marlise; VERONESE, Lauren Betina; SPIELMANN, Graziela; CKLESS, Lúcia Barth; SILVA, Eri Domingos da; ASSIS, Marilena. O Centro Municipal de Educação dos Trabalhadores Paulo Freire. In: MOLL, Jaqueline (org.). Educação de jovens e adultos. Porto Alegre: Mediação, 2004. p. 101-111.

ARROYO, Miguel G. A educação de jovens e adultos em tempos de exclusão. Construção coletiva: contribuições à educação de jovens e adultos. Brasília, DF: Unesco: MEC: RAAAB, 2005, p. 221-230.

ARROYO, Miguel G. Currículo, território em disputa. Petrópolis: Vozes, 2011.

BALZAN, Renan Luís; CUNHA, Elisa da Silva e. Da física à prática em conjunto musical: práticas interdisciplinares entre o ensino da acústica e a educação musical na EJA. In: ENCONTRO REGIONAL SUL DA ABEM, 28., 2018, Santa Maria. Anais [...]. Santa Maria: Abem, 2018. p. 1535-1549.

BRASIL. Ministério da Educação. Parecer $n^{\circ}$ 11, de 10 de maio de 2000. Dispõe sobre diretrizes curriculares nacionais para a educação de jovens e adultos. Brasília, DF: MEC, 2000. Disponivel em: http://portal.mec.gov.br/ secad/arquivos/pdf/eja/legislacao/parecer_11_2000.pdf. Acesso em: 3 set. 2020.

Ministério da Educação. Trabalhando com a educação de jovens e adultos: alunos e alunas da EJA, caderno 1. Brasília, DF: MEC, 2006. Disponivel em: http://portal.mec.gov.br/secad/arquivos/pdf/eja_caderno1. pdf. Acesso em: 17 ago. 2013.

- Ministério da Educação. Diretrizes curriculares nacionais gerais da educação básica. Brasilia, DF: MEC, SEB, DICEI, 2013.

CIAVATTA, Maria; RUMMERT, Sonia M. As implicações politicas e pedagógicas do currículo na educação de jovens e adultos. Educação \& Sociedade, Campinas, v. 31, n. 111, p. 461-480, 2010.

DUARTE, Karine Rayara Peres. Aula de música na educação de jovens e adultos. In: ENCONTRO REGIONAL SUDESTE DA ABEM, 11., 2018, São Carlos. Anais [...]. São Carlos: Abem, 2018. p. 1746-1754. 
FÁVERO, Osmar. Lições da história: os avanços de 60 anos e a relação de negação de direitos que alimentam as condições do analfabetismo no Brasil. In: PAIVA, Jane; OLIVEIRA, Inês Barbosa (org.). Educação de jovens e adultos. Petrópolis: DP et Alii, 2009. p. 9-21.

FERNANDES, José Nunes. Educação musical de jovens e adultos na escola regular: políticas, práticas e desafios. Revista da Abem, Porto Alegre, n. 12, p. 35-41, 2005.

FRACASSO, Daniela Cesa. O ensino de música no currículo da educação de jovens e adultos. In: ENCONTRO REGIONAL SUL DA ABEM, 18., 2018, Santa Maria. Anais [...]. Santa Maria: Abem, 2018. p. 1-13.

GONZAGA, Jennifer; GONÇALVES, Lilia Neves. A música na educação de jovens e adultos (EJA): um estudo sobre relações musicais entre diferentes grupos etários na escola. Olhares \& Trilhas, Uberlândia, v. 22, n. 1, p. 104$121,2020$.

GONZAGA, Jennifer; MORATO, Cíntia Thais. O ensino de música na educação de jovens e adultos (EJA): o caso de uma escola estadual em Araguari - MG. In: CONGRESSO NACIONAL DA ABEM, 23., 2017, Manaus. Anais [...]. Manaus: Abem, 2017, p. 1423-1440.

HENDERSON, Jucélia Estumano. Música na educação de jovens e adultos EJA: considerações sobre a construção do gosto musical. 2017. Dissertação (Mestrado em Artes) - Instituto de Ciências da Arte, Universidade Federal do Pará, Belém, 2017a.

O gosto musical de estudantes da modalidade de educação de jovens e adultos (EJA): habitus híbrido. In: CONGRESSO NACIONAL DA ABEM, 23., 2017, Manaus. Anais [...]. Manaus: Abem, 2017b. p. 1351-1366.

HENDERSON, Jucélia Estumano; HENDERSON, José Ruy; CHADA, Sonia Maria Moraes. Os (des)caminhos da educação musical em Belém do Pará: música na modalidade EJA. In: CONGRESSO NACIONAL DA ABEM, 23., 2017, Manaus. Anais [...]. Manaus: Abem, 2017. p. 1338-1352.

MACEDO, Elizabeth. Currículo e conhecimento: aproximações entre educação e ensino. Cadernos de Pesquisa, São Paulo, v. 42, n. 147, p. 716 737 , set./dez. 2012.

OLIVEIRA, Inês Barbosa de. Reflexões acerca da organização curricular e das práticas pedagógicas na EJA. Educar, Curitiba, n. 29, p. 83-100, 2007.

OLIVEIRA, Rafael Dias. Pensar e fazer música refletindo sobre o mundo: composição musical na EJA. Música na Educação Básica, Londrina, v. 7, n. $7 / 8$, p. $72-85,2016$. 
OLIVEIRA, Rafael Dias; BEINEKE, Viviane. Composição, diálogo e conscientização na EJA: um estudo no campo da educação musical. Educação, Santa Maria, v. 45, p. 1-31, 2020.

OSCAR, Sérgio Cândido de; BASTOS, Juliana Curzi. O ensino de música na modalidade EJA: psicologia da música e estratégias de motivação para o desenvolvimento musical de adultos. In: CONGRESSO NACIONAL DE ARTE/EDUCADORES DO BRASIL, 26., 2016, Boa vista. Anais [...]. Boa Vista: Confaeb, 2016. p. 897-906.

PRAZERES, Flávia Costa; MACHADO, Daniela Dotto. Uma breve revisão de literatura sobre a importância e as possibilidades do ensino de Arte/Música na EJA. In: CONGRESSO NACIONAL DA ABEM, 20., 2011, Vitória. Anais [...]. Vitória: Abem, 2011. p. 2334-2343.

PREFEITURA MUNICIPAL DE PORTO ALEGRE. Ordem de serviço n.002, de 12 de fevereiro de 2008. Porto Alegre: Prefeitura Municipal de Porto Alegre, 2008. Disponivel em: http://www2.portoalegre.rs.gov.br/cgibin/nph-brs?s 1=000029621.DOCN.\&l=20\&u=/netahtml/sirel/simples . html\&p=1\&r=1\&f=G\&d=atos\&SECT1=TEXT. Acesso em: 3 set 2020.

Secretaria Municipal de Educação. Centro Municipal de Educação dos Trabalhadores Paulo Freire. Projeto politico-pedagógico. Porto Alegre: CMET Paulo Freire, [2014]. Disponivel em https://websmed.portoalegre. rs.gov.br/escolas/cmet/material/PPP.pdf. Acesso em: 3 set. 2020.

RIBAS, Maria Guiomar de Carvalho. Música na educação de jovens e adultos: um estudo sobre práticas musicais entre gerações. 2006. Tese (Doutorado em Música) - Instituto de Artes, Universidade Federal do Rio Grande do Sul, Porto Alegre, 2006a.

Música e intergeracionalidade na educação de jovens e adultos. In: CONGRESSO DA ANPPOM, 26., 2006, Brasília, DF. Anais [...]. Brasília, DF: Anppom, 2006a. p. 68-72.

Práticas musicais na educação de jovens e adultos: uma abordagem geracional. Revista da Abem, Porto Alegre, n. 21, p. 124-134, 2009.

Mulheres da educação de jovens e adultos em busca da formação perdida: um olhar da educação musical. Educar em Revista, Curitiba, n. 53, p. 113-130, 2014.

SAÚL, Tiago Scalvenzi. O ensino de música na EJA: saberes docentes de professores dos CEEBJAs de Curitiba-PR. 2013. Dissertação (Mestrado em Música) - Setor de Ciências Humanas, Letras e Artes, Universidade Federal do Paraná, Curitiba, 2013. 
SOUZA, Maria Antônia de. Educação de jovens e adultos. Curitiba: Ibpex, 2011.

VIEIRA, Djenane. Entre risos e rimas: criação musical e protagonismo em classes de EJA. In: CONGRESSO NACIONAL DA ASSOCIAÇÃO BRASILEIRA DE EDUCAÇÃO MUSICAL, 23., 2017, Manaus. Anais [...]. Manaus: Abem, 2017. p. 1456-1468.

WOLFFENBÜTTEL, Cristina Rolim; SANT'ANNA, Sita Mara Lopes. O estado da arte nas pesquisas envolvendo EJA e educação musical. In: SEMINÁRIO NACIONAL DE ARTE E EDUCAÇÃO, 26., 2018, Montenegro. Anais [...]. Montenegro: Fundarte, 2018. p. 622-628. 
Daniela Cesa Fracasso é licenciada em Música e mestra em Música/Educação Musical pela Universidade Federal do Rio Grande do Sul (UFRGS). Professora da educação básica há 15 anos, atua na educação de jovens e adultos desde 2008. Em 2011 passou a integrar o quadro de professores efetivos da área de Educação Musical do Colégio de Aplicação da UFRGS. Coordenou a educação de jovens e adultos na mesma instituição nos anos de 2015, 2017 e 2019. É integrante do Grupo de Pesquisa Música e Escola (CNPq/UFRGS) e direciona seus estudos, principalmente, ao ensino de música na educação básica, com ênfase na educação de jovens e adultos. https://orcid.org/0000-0002-9499-3001 